Chirurgia (2021) 116: 162-169

No. 2, March - April

Copyright@ Celsius

http://dx.doi.org/10.21614/chirurgia.116.2.162

\title{
A Better Understanding of Axillary Lymph Node Dissection in the Era of Sentinel Lymph Node Biopsy
}

\author{
Silviu Cristian Voinea ${ }^{1,2}$, Angela Sandru ${ }^{1 *}$, Cristian Ioan Bordea ${ }^{1,2}$, Aniela Noditi ${ }^{1,2}$, Lacramioara Paula Borangic ${ }^{1}$, \\ Alexandru Blidaru ${ }^{1,2}$
}

'Department of Surgical Oncology, Institute of Oncology "Prof Dr Alex. Trestioreanu" Bucharest Romania

2“Carol Davila" University of Medicine and Pharmacy, Bucharest, Romania

${ }^{*}$ Corresponding author:

Angela Sandru, MD, PhD

"Prof. Dr. Alexandru Trestioreanu"

Institute of Oncology Bucharest

Romania

E-mail: sandruangela@gmail.com

\section{Rezumat \\ Un update al rolului limfadenectomiei axilare în era ganglionului santinelă}

Limfadenectomia axilară a fost şi rămâne o parte importantă a tratamentului cancerului mamar, deşi introducerea tehnicii de biopsie a ganglionului santinelă a revoluționat chirurgia cancerului mamar. Biopsia ganglionului santinelă furnizează aceleaşi informații prognostice ca şi limfadenectomia axilară, dar cu o morbiditate semnificativ mai redusă. Numeroasele trialuri randomizate desfăşurate în ultimii 20 de ani au impus biopsia ganglionul santinelă ca standardul de aur în tratamentul cancerului mamar incipient. Limfadenectomia axilară reprezintă o intervenție standardizată cu repere şi limite clare, bine definite. O tehnică precisă şi o bună cunoaştere a anatomiei axilei sunt necesare pentru o limfadenectomie axilară completă şi corectă. Din păcate însă, nici aplicarea unei tehnici atente şi meticuloase de disecție nu garantează lipsa complicațiilor, doar limitarea lor. In prezent indicațiile limfadenectomiei axilare sunt într-o continuă schimbare, dar procedeul are încă un rol indiscutabil în tratamentul cancerului mamar.

Cuvinte cheie: limfadenectomie axilară, ganglion santinelă, cancer mamar, anatomia axilei

\section{Abstract}

Axillary lymph node dissection (ALND) was and still is an 
important part of breast cancer treatment despite the fact the sentinel lymph node biopsy (SLNB) has revolutionized breast cancer surgery. SLNB provides the same prognostic information as ALND but with significantly less morbidity. The results of numerous trials conducted over the past 20 years have crowned SLNB as the gold standard for early breast cancer treatment. ALND represents a very standardized intervention with precise landmarks and boundaries. An accurate technique and a good knowledge of axilla' anatomy are mandatory for a correct and complete ALND. But even with a meticulous and careful technique of dissection, a comprehensive ALND may be associated with important morbidity. Nowadays ALND indications are continuously evolving, but the procedure has still an indisputable place in breast cancer treatment.

Key words: axillary lymph node dissection, sentinel lymph node biopsy, breast cancer, anatomy of the axilla

\section{Introduction}

Axillary evaluation is of utmost importance in invasive breast cancer (IBC) due to its role in staging, treatment (removal of metastatic nodes), prognosis, and postoperative decisions (indication of adjuvant therapy).

Axillary lymph node dissection (ALND) has been an important chapter of breast cancer surgery (BCS) for more than 100 years. But the development of more conservative approaches has narrowed axillary surgery magnitude with axillary complete dissection being reserved for carefully selected cases according to precise criteria.

In recent years, the usefulness of ALND has been questioned mainly because of its inherent morbidity with no obvious increase in survival in early breast cancer. But although ALND is associated with potentially important morbidity, a meticulous surgical technique may significantly reduce immediate and late complications, so that mastering the correct technique is essential for surgeons approaching the field of breast cancer surgery.

\section{Background}

The trend towards de-escalation from radical procedures towards more conserving ones led to the widespread use of the sentinel lymph node biopsy (SLNB) technique.

The SLNB provides the same information as ALND but with significantly less morbidity, being considered a revolutionary concept in the surgical treatment of cancer. The histology of the first lymph node (named SLN) is deemed representative for all the other nodes from that specific lymph basin and so, if SLN is negative, complete lymph node dissection is avoided. Thus, according to the ALMANAC trial, by implementing the SLNB technique, the incidence of sequelae associated with ALND has been reduced by half (1).

In patients with early breast cancer (EBC) and clinically negative axilla, the probability of finding a positive SLN is only $20 \%-30 \%$, and therefore, primary ALND is considered overtreatment and has become obsolete in these cases (2).

Going further, studies have shown that even in patients with a metastatic SLN, the probability of having a non-sentinel lymph node (NSLN) involvement is somewhere between $40-60 \%$ (3), meaning that in almost $50 \%$ of patients with positive SLN, ALND does not bring any benefit. So the usefulness of ALND began to be questioned even in some EBC patients with neoplastic deposits in SLN. Many prospective randomized controlled trials aimed to clarify this issue.

The American College of Surgeons (ACOSOG) Z0011 trial showed that in women with early breast cancer (T1/T2) and metastases in 1 or 2 SLN, without extranodal extension, that undergo breast conserving 
therapy (BCT) and adjuvant systemic therapy, the omission of ALND does not decrease overall survival, nor increase axillary recurrence (4).

International Breast Cancer Study Group Trial 23-01 (IBCSG 23-01) found that in women with tumors $\leq 5 \mathrm{~cm}$ and 1 or 2 minimal involved SLN, non-sentinel axillary nodes were metastatic in only $13 \%$ of cases. The authors concluded that ALND should be avoided in women that receive breast conserving surgery and adjuvant systemic therapy if they fulfill the above-mentioned conditions (5).

AMAROS trial showed that ALND and axillary radiotherapy after a positive SLN provide comparable axillary control for patients with T1-2 primary breast cancer and no palpable lymphadenopathy. The 2 groups have similar disease free and overall survival, but axillary radiotherapy resulted in significantly less morbidity than ALND (6).

So, SLNB has become the standard of care as a staging procedure in clinically node-negative early breast cancer patients with ALND being considered superfluous in more than half of these cases (7). NSLN metastasis is correlated with patients' age, pathologic tumor size, grade, histology, multifocality, hormone receptor status, $\mathrm{Ki}^{-}$ 67, c-erbB-2 expression and lymphovascular space involvement.

Worldwide accepted guidelines state that ALND should be reserved for (NCCN, ESMO):

- inflammatory and locally advanced breast cancer

- cases with metastatic SLN who do not meet the Z0011 trial criteria

- the failure of SLN identification

- persistent tumoral foci in SLN after neoadjuvant chemotherapy

- cases with proven axillary invasion preoperatively (core needle biopsy of the lymph node) where no neoadjuvant chemotherapy is intended

- cases with previous axillary surgery for another disease

\section{The ALND Technique}

The goal of ALND is to remove the axillary lymph nodes (ALN) and the associated fat tissue without causing damages to the functional axillary structures (blood vessels and nerves). ALND for IBC can partially (I and/or II Berg levels) or completely remove the nodes (I, II and III Berg levels), depending on the extent of lymph nodes involvement. It may be performed after mastectomy or BCT and currently, involves the removal of Berg levels I and II lymph nodes aiming to diminish the negative consequences of an extended dissection.

ALND accompanying mastectomy is easier and safer to perform because the skin incision for mastectomy offers a good exposure of the axilla's content. Following BCS, ALND is performed frequently through a separate, smaller incision, preferably along a skin crease. Usually, the incision is a curving transverse one, placed between the pectoralis major and latissimus dorsi muscle, but several different incision lines can be used (more often transversals than longitudinals).

Thorough knowledge of axilla anatomy represents the cornerstone for every surgeon who intends to perform ALND in breast cancer. Accurate identification of the fascia, nerves, blood and lymphatic vessels, as well as their relationship with other anatomical landmarks of the axilla, has strategic importance for their preservation during ALND procedure (8).

The boundaries of a precise and complete ALND are (Fig. 1):

- superior: the axillary vein;

- inferior: the interdigitations between latissimus dorsi and serratus anterior muscle;

- medial: the chest wall;

- lateral: latissimus dorsi muscles.

ALN drain lymph vessels from the lateral quadrants of the breast, the superficial lymph vessels from the chest wall, the abdomen above the umbilicus, and the vessels from the upper limb. On average there are 20 to 30 ALN, though the exact number varies widely 


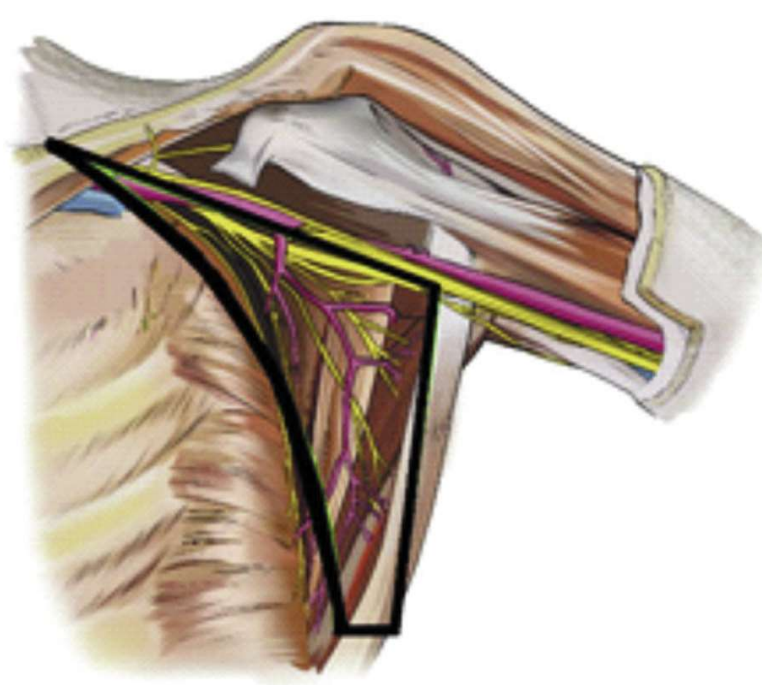

Figure 1. Boundaries of the axilla

between individuals, going up to 65 in some resected specimens of lymphadenectomy (9).

ALN are divided into several groups according to their location in the armpit. From a surgical and oncological point of view, the most useful is Berg classification (Fig. 2). Berg divided the axillary lymph nodes into three levels in relation to the pectoralis minor muscle (10):

- the first level (inferior axilla) contains the lymphatic tissue situated laterally from the lateral border of the pectoralis minor muscle;

- the second level (middle axilla) contains the lymphatic tissue between the borders and behind the pectoralis minor muscle;

- the third level (upper axilla) contains the lymphatic tissue situated medially from the medial border of the pectoralis minor muscle.

The majority of early and screen-detected breast cancers drain primarily to levels I and II ALN, the tumor invasion pattern being in most cases sequential (11). But surgeons, radiologists, and radiation oncologists should be aware that ALN classification based on muscle boundaries varies significantly with changes in arm position, thus making objective comparisons of information collected in different arm positions unreliable (12).

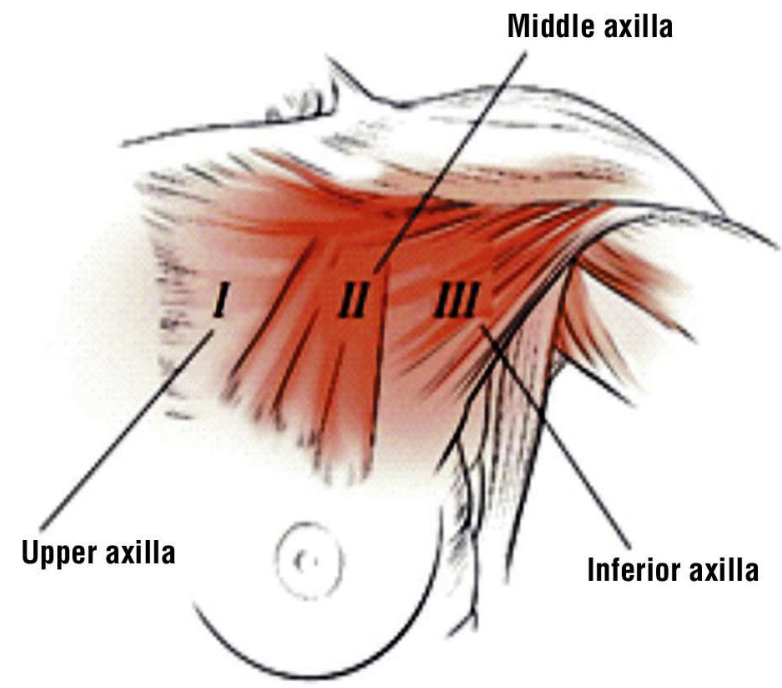

Figure 2. Berg classification

The structures that are routinely identified and preserved at the time of ALND are:

- the axillary vein;

- the axillary artery - always placed lateral (cranial) to the vein;

- the brachial plexus;

- the long thoracic nerve (Charles Bell);

- the thoracodorsal pedicle (the vessels and nerve).

The lateral thoracic pedicle and pectoral muscles pedicle are constant anatomical structures of the axilla and should be preserved whenever is possible.

Some anatomical structures are not well described, with little pieces of information on their location, path, or possible branching, for example:

- the medial cutaneous nerve of the arm (MCNA) which is responsible for the sensitivity of the medial distal third of the arm; it may be identified or not at the moment of ALND;

- the intercostobrachial nerves (ICBN).

The ICBN are responsible for the sensitivity of the internal and proximal regions of the arm. Up to 3 ICBN were identified and may pass through the axilla simultaneously at different levels. Several studies have demonstrated a significant sensory benefit when the IBCN are preserved (13), although there are some reports 
that state that sectioning the ICBN does not always result in loss of sensation in the arm. There is currently no consensus on the optimal handling of ICBN during ALND (14, 15). Anastomosis between MCNA and ICBN is relatively uncommon.

There are more deviations from what normal anatomy of the axilla is considered, by normal meaning the most frequently encountered situation. These uncommon findings are insufficiently described in the medical literature and may represent major intraoperative distress for young surgeons. Rare anatomical structures identified in the axilla are:

- duplication of the axillary vein (16);

- presence of the chondrotrochlearis muscle that originates from the pectoral major muscle (17,18);

- presence of the Langer's axillary arch, a very rare anatomical variation of latissimus dorsi muscle insertion who pass to the pectoralis muscles and can push the axillary vessels during the hyper abduction of the arm $(19,20)$;

- complete or partial absence of the pectoralis major and/or minor muscles (21);

- variation of the origins of the pectoralis major and latissimus dorsi muscles (21);

- presence of the pectoralis quartus muscle (21).

Being aware of these possible unusual variants you may avoid unpleasant intraoperative accidents and therefore, surgeons must pay attention to at least two issues during routine ALND (8):

- anatomical structures not identified in the location described in anatomy atlases;

- anatomical structures identified in unexpected locations.

So only after acknowledgment and careful dissection of these abnormal patterns, surgeons should handle them in the safest way for the patient.

The dissection usually starts in the upper axilla (Berg level III), for a proper dissection being important to expose adequately and early the pectoralis minor muscle. The pectoralis major muscle is retracted medially and the lateral border of the pectoralis minor is dissected in order to visualize the axillary vein, this being the key element of the dissection. No further dissection is carried on until the axillary vein is well exposed. Then, the clavipectoral fascia is divided and the long thoracic nerve is sought after and identified either by palpation or direct visualization. The descending ventral branches of the axillary vein usually need to be dissected. Care should be taken not to clear completely the perivascular fascia and the fatty tissue surrounding the axillary vein.

The pectoralis minor muscle is retracted medially, the axillary tissue that runs posterior to the muscle is visualized and axillary dissection of the upper axilla can be performed. Other approaches are also described: transpectoral or concomitant transpectoral and standard procedure. Then, the latissimus dorsi muscle is dissected with the identification and preservation of the thoracodorsal and subscapular pedicle. The dissection of the inferior and middle axilla is done en bloc with subscapularis fascia. The fascia of the serratus anterior muscle may be cleared but the long thoracic nerve must be spared. However, if there are bulky lymph nodes in the area of the thoracodorsal pedicle or long thoracic nerve, these structures may be sacrificed to realize the complete dissection. Whenever is possible, the entire axillary content should be removed as a single specimen.

The dissection can begin also from the caudal part of the axilla (Berg level I) and then continuing medially with the Berg level II and/or lever III. The lymphatic tissue between the pectoralis muscles must be also removed carefully (the interpectoral Rotter's nodes are part of the Berg level II), after sparing the pectoralis pedicle.

After ALND, careful verification of the entire axilla must be performed and any remaining suspicious lymph nodes should be removed. Meticulous hemostasis is necessary.

We consider the closure of axillary space as the best option in preventing seroma formation because reducing the dead space is pivotal. Suction drainage is placed in the axilla and exteriorized through a stab wound. 
The drain will be preserved depending on the amount of lymph accumulation, with most surgeons tending to remove the drain when the drainage volume is less than $30-50 \mathrm{ml} / 24$ $\mathrm{h}$. It is believed that meticulous attention to minimize leakage from dissected blood and lymphatic vessels and to obliterate the dead space may reduce the incidence of seroma formation, though the subject is controversial. Several studies claim that closure of the axilla and close wound drainage seem to not reduce the seroma formation or the number of seroma aspiration manoeuvers (22). There are no randomized trials on this topic so it is hazardous to draw a firm conclusion.

\section{Complications of ALND}

In the surgical treatment of breast cancer, ALND is considered primarily responsible for functional sequelae in the arm ipsilateral to the lymph node dissection.

In the ACOSOG Z0011 trial, approximately $75 \%$ of the ALND patients had a complication compared to only $25 \%$ of the SLNB group (23). The results are even more favorable to SLNB as there were no significant differences in overall survival, disease-free survival and local or regional recurrence between SLNB and ALND groups (24). The SLNB procedure is indeed safer and improves patient's quality of life, but is not completely free of undesirable sequelae, as most studies show. In the literature, the complication rate of both interventions varies widely depending on many factors: number of lymph node excised, patient's education level, body mass index or age (25).

A lot of complications may appear after ALND, such as:

- Bleeding after intraoperative injuries of axillary, subscapularis or thoracodorsalis vessels or postoperative hematomas formation;

- Pain (acute or chronic);

- Axillary vein thrombosis;

- Postoperative infections (1-20\% in different statistics) (2);

- Seromas - the reported incidence of seroma varies greatly, ranging from $3 \%$ to more than $90 \%$. Seroma formation has been related to the extent of axillary lymph node involvement, type and extent of breast surgery (more common after mastectomy than after BCT) and the use of electrocautery (26);

- Injury of the thoracodorsalis nerve results in weakness during abduction and medial rotation of the shoulder;

- Long thoracic nerve injury determine winging of the scapula (the medial edge of the scapula protrudes involuntary and uncomfortably from the posterior thoracic wall);

- Injury of the pectoralis nerves causes different degrees of pectoralis major muscle atrophy;

- Numbness of the skin in the upper inner arm after the ICBN sectioning;

- Shoulder stiffness after a long immobilization;

- Brachial plexopathy after injuries of brachial plexus during dissection of the axilla or after extreme manipulations of the arm. The result is temporary weakness of the upper extremity or even paralysis. The solution is intense physical therapy;

- The axillary web syndrome or lymphatic cordings is defined by the presence of a rope-like structure in the subcutaneous tissue of the axilla, due to lymphatic pathology. Usually, physical therapy solves the complications in 2-3 months, but not in all patients. Sometimes it can persist for years after surgery and may reoccur after resolution (27);

- Breast and upper limb lymphedema are the most feared, frustrating and potentially disabling complications after ALND. Clinical manifestations of lymphedema include swelling (an increase in limb volume by $\geq 10 \%$ ), induration, skin changes, and decreased functionality of the affected limb.

The pooled incidence of breast cancer treatment-related lymphedema following ALND is $22.3 \%$ (range, $11 \%-57 \%$ ), whereas 
that following SLNB is $6.3 \%$ (range, $0 \%-23 \%$ ) (28). The exact incidence of lymphedema among breast cancer survivors varies and largely depends on the type of treatment received, with patients undergoing ALND plus radiotherapy having the highest incidence. Other risk factors are: older age, obesity, infections, genetic susceptibility, and taxanebased chemotherapy (29).

Lymphedema is a chronic disease that can be difficult to treat and is often associated with both physical and psychological morbidity, that's why prevention of this complication is of paramount importance. In many centers, at the time of ALND, there is a constant effort to preserve the lymphatic drainage of the arm and consequently minimize the risk of lymphedema. Axillary reverse mapping (ARM) studies have demonstrated that ARM-specific nodes seldom harbor metastatic involvement from breast cancer (30).

Because several studies have shown an increased incidence of lymphedema with the number of ALN removed, there is a unanimous agreement that removal of at least 10 ALN is adequate and sufficient for a reliable lymph node staging (31).

\section{Conclusions}

The improvement and refinement of operative techniques is a continuous concern of oncologic surgery. ALND assumes a deep knowledge of the axilla anatomy and for these reasons, ALND represents a very standardized intervention. The indications of ALND are evolving and depend primarily on the infrastructure of each medical center, but also the experience and training of the medical staff.

\section{Acknowledgements}

To Carmen Dumitru who provided the illustrated material.

\section{Author's Contributions}

The authors have equal contribution to the paper.

\section{Conflicts of interest}

The authors declare no conflict of interests.

\section{Ethics of Approval}

Ethical approval was not needed for this retrospective study.

\section{References}

1. Fleissig A, Fallowfield LJ, Langridge Cl, Johnson L, Newcombe RG, Dixon JM, et al: Post-operative arm morbidity and quality of life. Results of the ALMANAC randomised trial comparing sentinel node biopsy with standard axillary treatment in the management of patients with early breast cancer. Breast Cancer Res Treat. 2006; 95(3):279-93.

2. Singhal H. Axillary Dissection, Overview, Periprocedural care. Medscape 14.04.2019

3. Zheng J, Cai S, Song H, Wang Y, Han X, Wu H, et al: Positive non-sentinel axillary lymph nodes in breast cancer with 1-2 sentinel lymph node metastases. Medicine (Baltimore). 2018;97(44): e13015.

4. Giuliano AE, Ballman KV, McCall L, Beitsch PD, Brennan MB, Kelemen PR, et al: Effect of Axillary Dissection vs No Axillary Dissection on 10-Year Overall Survival Among Women With Invasive Breast Cancer and Sentinel Node Metastasis: The ACOSOG Z0011 (Alliance) Randomized Clinical Trial. JAMA. 2017;318(10): 918-926.

5. Galimberti V, Cole BF, Zurrida S, Viale G, Luini A, Veronesi P, et al: Axillary dissection versus no axillary dissection in patients with sentinel-node micrometastases (IBCSG 23-01): a phase 3 randomised controlled trial. Lancet Oncol. 2013;14(4):297-305.

6. Donker M, Tienhoven G, Straver ME, Meijnen P, van de Velde CJH, Mansel RE, Cataliotti L, et al: Radiotherapy or surgery of the axilla after a positive sentinel node in breast cancer (EORTC 10981-22023 AMAROS):a randomised, multicentre, open-label, phase 3 non-inferiority trial. Lancet Oncol. 2014;15(12):1303-1310.

7. Güven HE, Doğan L, Kültüroğlu MO, Gülçelik MA, Özaslan C. Factors Influencing Non-sentinel Node Metastasis in Patients with Macrometastatic Sentinel Lymph Node Involvement and Validation of Three Commonly Used Nomograms. Eur J Breast Health. 2017; 13(4):189-193.

8. Silva Soares EW. Anatomical variations of the axilla. Springerplus 2014; 3:306.

9. Boughey JC, Donohue JH, Jakub JW, Lohse CM, Degnim AC. Number of lymph nodes identified at axillary dissection: effect of neoadjuvant chemotherapy and other factors. Cancer. 2010; 116(14):3322-9.

10. Berg JW. The significance of axillary node levels in the study of breast carcinoma. Cancer 1955:8(4):776-8

11. Maxwell F, Mellon CM, Bricout M, Cauderlier E, Chapelier M, Albiter Met al: Diagnostic strategy for the assessment of axillary lymph node status in breast cancer. Diagn Interv Imaging. 2015;96(10): 1089-101.

12. Saito Al, Vargas C, Benda R, Morris CG, Mendenhall NP. Is the Berg axillary lymph node categorization useful in the $3 \mathrm{D}$ environment? Am J Clin Oncol. 2007;30(1):69-77.

13. Henry BM, Graves MJ, Pekala JR, Sanna B, Hsieh WC, Tubbs RS, et al: Origin, Branching, and Communication of the Intercosto-brachial Nerve: A Meta-Analysis with Implications for Mastectomy and Axillary Lymph Node Dissection in Breast Cancer. Cureus 2017:9(3):e1101.

14. Warrier S, Hwang $\mathrm{S}$, Koh $\mathrm{CE}$, Shepherd $\mathrm{H}$, Mak $\mathrm{C}$, Carmalt $\mathrm{H}$, et al. Preservation or division of the intercostobrachial nerve in axillary dissection for breast cancer: meta-analysis of randomised controled trials. Breast. 2014;23(4); 310-6.

15. Andersen KG, Aasvang EK, Kroman N, Kehlet $\mathrm{H}$. Intercostobrachial nerve handling and pain after axillary lymph node dissection for breast cancer. Acta Anaesthesiol Scand. 2014;58(10):1240-8. 
16. Paixao P, Gomes AP, Sousa MSC, Santiago I, Germano ASCC, Amadora PT. Normal vascular variants of the upper extremity. EPOS Poster ECR 2014 / C-1039.

17. Samuel VP, Vollala VR. Unusual pectoralis major muscle: the chontroepitrochlearis. Anat. Sci. Int. 2008. Publimed, Anat Sci Int, 2008;83(4): 277-9.

18. Di Gennaro GL, Soncini G, Andrisano A, Valdiserri L. The chondroepitrochlearis muscle: case report. Chir Organi Mov. Publimed. 1998; 83(4):419-23.

19. Effraimidou E. Axillary Arch: Disorientating the Axilla. Clinics in Surgery. Remedy Publications. 2017;2:article 1687.

20. Jelev L, Georgiev GP, Surchev L. Axillary arch in human: common morphology and variety. Definition of "clinical" axillary arch and its classification. Ann Anat Anat Anz Off Organ Anat Ges. 2007;189(5):473-81.

21. Kutiyanawala M A, Stotter $A$, Windle R. Anatomical variants during axillary dissection. British Journal of Surgery March. 1998; 85(3):393-4.

22. Taylor JC, Rai S, Hoar F, Brown H, Vahwanath L. Breast cancer surgery without suction drainage: the impact of adopting a "no drains" policyon symptomatic seroma formation rates. Eur J surg Oncol 2013;39(4):334-8.

23. Lucci A, McCall LM, Beitsch PD, Whitworth PW, Reintgen DS, Blumencranz PW, et al: Surgical complications associated with sentinel lymph node dissection (SLND) plus axillary lymph node dissection compared with SLND alone in the American College of Surgeons Oncology Group Trial Z0011; J Clin Oncol. 2007 Aug 20;25(24):3657-63.
24. Li CZ, Zhang P, Li RW, Wu CT, Zhang XP, Zhu HC. Axillary lymph node dissection versus sentinel lymph node biopsy alone for early breast cancer with sentinel node metastasis: A meta-analysis. Eur J Surg Oncol. 2015; 41(8):958-66.

25. Kozak D, Głowacka-Mrotek I, Nowikiewicz T, Siedlecki Z, Hagner W, Sowa M, Zegarski W. Analysis of Undesirable Sequelae of Sentinel Node Surgery in Breast Cancer Patients - a Prospective Cohort Study. Pathol Oncol Res. 2018:24(4):891-897.

26. Bastelaar J, Roozendaal LM, Meesters-Caberg M. Surgical removal of fibrous axillary seroma pocket and closing of dead space using a lattisimus dorsi flap. Journal of Surgical Case Reports. 2018;3:1-3.

27. Koehler LA, Haddad TC, Hunter DW, Tuttle TM. Axillary web syndrome following breast cancer surgery: symptoms, complications, and management strategies. Breast Cancer (Dove Med Press). 2018;11:13-19.

28. Shaitelman SF, Cromwell KD, Rasmussen JC, Stout NL, Armer JM, Lasinski $\mathrm{BB}$, Cormier $\mathrm{JN}$. Recent progress in the treatment and prevention of cancer-related lymphedema. CA Cancer J Clin. 2015; 65(1):55-81.

29. Ayre K, Parker K. Lymphedema after treatment of breast cancer: a comprehensive review. J Unexplored Med Data. 2019;4:5

30. Shao X, Sun B, Shen Y. Axillary reverse mapping (ARM): where to go. Breast Cancer. 2019;26:1-10

31. National Comprehensive Cancer Network (2021) NCCN, Invasive Cancer, Surgical Axillary Staging. https://www.nccn.org/professionals/ physician_gls/pdt/breast.pdf. Accessed march 2021. 